\title{
Assessment of the Level of Knowledge of the Nature of Highly Pathogenic Avian Influenza Demonstrated by the Nigerian Veterinary Laboratory Staff Involved in HPAI Diagnosis in Nigeria
}

\author{
Bello Rabi'u Alkali', Kyauta Bulus Tanyigna², Yahaya Abubakar Yabo ${ }^{3}$ \\ ${ }^{1}$ Department of Veterinary Microbiology, Usmanu Danfodiyo University, Sokoto, Nigeria \\ ${ }^{2}$ National Institute for Policy and Strategic Studies (NIPSS), Kuru Jos, Nigeria \\ ${ }^{3}$ Department of Veterinary Physiology and Biochemistry, Usmanu Danfodiyo University, Sokoto, Nigeria \\ Email: balkali@yahoo.co.uk
}

Received 14 March 2015; accepted 14 April 2015; published 15 April 2015

Copyright (C) 2015 by authors and Scientific Research Publishing Inc.

This work is licensed under the Creative Commons Attribution International License (CC BY).

http://creativecommons.org/licenses/by/4.0/

cc) (i) Open Access

\begin{abstract}
The study was designed to evaluate the level of knowledge of Nigerian Veterinary Laboratory Staff on the nature of Highly Pathogenic Avian Influenza (HPAI) disease using structured questionnaires. The study comprised the Staff of National Veterinary Research Institute (NVRI) and five reference Veterinary Teaching Hospitals (VTH) designated for HPAI diagnosis. A total of 69 questionnaires were distributed to the laboratory staff. Questions on the general nature of the disease such as the cause, signs, mode of transmission, methods of identification, lesions, control and prevention, etc. were asked. The results showed that $77.38 \%$ of the staff answered all the questions correctly indicating their considerable knowledge of the HPAI disease. Considerable percentage of the staff listed correctly the equipment used for serology (36.23\%) and RT-PCR (31.88\%). Interestingly only $13.04 \%$ of the staff listed correctly the equipment used in rapid tests despite the fact that they are simpler and recommended for all P2 laboratories. In conclusion, the veterinary laboratory staff assessed demonstrated a significant level of knowledge on HPAI diagnosis; however, most of their laboratories lack the structure, organization, funds and basic facilities required for effective HPAI diagnosis.
\end{abstract}

\section{Keywords}

Assessment, Veterinary, Laboratory, Highly Pathogenic Avian Influenza 


\section{Introduction}

Avian influenza is primarily a disease of poultry caused by a virus of the family Orthomyxoviridae, genus influenza virus A, and was commonly referred to as fowl plague in the past and now Highly Pathogenic Avian Influenza (HPAI) [1]. The history of HPAI dates back to the 16th century within which at least 24 pandemics have occurred in Europe, Asia, America and Africa. The influenza of 1918 was described as the mother of all pandemics and was responsible for over 50 million deaths worldwide [2]. The virus was first reported as Highly Pathogenic Avian Influenza or HP AI ("fowl plague") in 1878 by Perruacito in Italy and was subsequently reported in South Africa in 1961, USA in 1971, Australia in 1975, England in 1979, Ireland in 1983, Mexico in 1994 and Pakistan in 1994 [3]. HPAI became a topical issue in Asia including Peoples Republic of China in 1996, Hong Kong in 1997, 2001, 2002 and 2003, Cambodia, Indonesia, Japan, Malaysia, Republic of Korea, Laos, Taiwan, Thailand, Vietnam, Turkey and Romania in 2005 [4]. In Nigeria, there was no evidence of clinical disease from HPAI until 22nd January 2006 when the disease was first reported in Sambawa farms, Kaduna and confirmed by the International Office of Epizootics, World Reference Laboratory, Padova, Italy, on 7th February, 2006 [5].

On realizing that Highly Pathogenic Avian Influenza (HPAI) could be a disaster to the poultry industry and that it poses a major threat to public health, the Federal Government of Nigeria in 2006 immediately constituted a Technical Committee of Experts on Prevention and Control of Avian Influenza to develop strategies for the prevention of the disease, develop a surveillance network against the disease and prepare an emergency preparedness plan for the disease [6]-[8].

The committee noted that the threat to human health would persist as long as the problem persisted in livestock and poultry flocks. Therefore, the committee recommended that the primary focus of attention in the prevention and perpetuation of the virus in the country should be on the animal health perspective. Moreover, all evidence of people who have been infected with avian flu indicated that close contact with dead or sick birds was the principal source of human infection [4] [5] [7] [9]. Also, all other risk factors of human infection so far reported were associated with involvement with poultry processing or consumption of infected birds [7].

The expert committee further recommended an effective animal disease surveillance, both passive and active (including random and targeted surveillance) in domestic and wild birds countrywide including poultry markets, wetlands and poultry located along the known routes of migratory birds, poultry abattoirs, borders, targeted farms and rural poultry [8]. The aim was to prevent the introduction of the virus into the country, and if inadvertently introduced, to propose a system of rapid and efficient laboratory diagnosis and confirmation of cases which would enable equally rapid and prompt control measures to prevent the spread of the infection and its attendant economic loss, public health implications and social disruption. The effort of the federal government could only make meaning if all stake holders particularly the veterinarians and their technology have the basic understanding of the general nature of the disease.

\section{Materials and Methods}

The assessment of the level of knowledge of the veterinary laboratory staff involved in the diagnosis of HPAI in Nigeria was evaluated using a structured semi closed open ended questionnaire. Questions on the general nature of the disease such as the cause, signs, mode of transmission, methods of identification, lesions, control and prevention, etc. were asked. Responses were collated and results presented in tables and charts. Inferences were drawn using inferential statistics.

\section{Results and Discussion}

\subsection{Staff Knowledge in Respect of HPAI}

The result showed that, the largest percentage of the staff demonstrated considerable knowledge of the nature of HPAI disease came from NVRI (21.25\%), followed by those of Ibadan (16.5\%), Maiduguri (12.63\%), Nsukka (10.25\%), Sokoto (9.25\%) and Zaria (7.5\%).

\subsection{Staff Knowledge in Respect of Basic HPAI Diagnostic Equipment}

Assessment of the staff knowledge in respect of basic equipment used in the diagnosis of HPAI disease showed 
considerable percentage of the staff listed correctly the equipment used for serology (36.23\%) and RT-PCR (31.88\%) as depicted in Figure 1 below. This result further indicated that, although more staff are knowledgeable about the equipment used in RT-PCR technique only 16.3\% can perform the technique. Also only 13.04\% of the staff correctly listed the equipment used in Rapid tests despite the fact that they are simpler and recommended for all P2 laboratories.

When the respondents were asked to indicate whether they can operate HPAI diagnostic equipment in their laboratories, $58 \%$ of the respondents indicated yes while $14.5 \%$ responded negatively (Figure 2). This revealed that majority of the staff could operate the facilities available in their laboratories. Although these facilities are mostly for serological technique as earlier indicated.

\section{Conclusion}

The veterinary staff in Nigeria involved in HPAI diagnosis appeared to be knowledgeable about the nature of the HPAI disease, its diagnostic methodologies and operational equipment used in its diagnosis. However Veterinary Teaching Hospitals lacked the structure, organization, funds and basic facilities required for effective HPAI and TDAs diagnosis as recommended by OIE and the Nigerian veterinary authorities. NVRI appeared to be the only institute in the country that has adequate staff and competency, structure and facilities to carry out effective HPAI diagnosis.

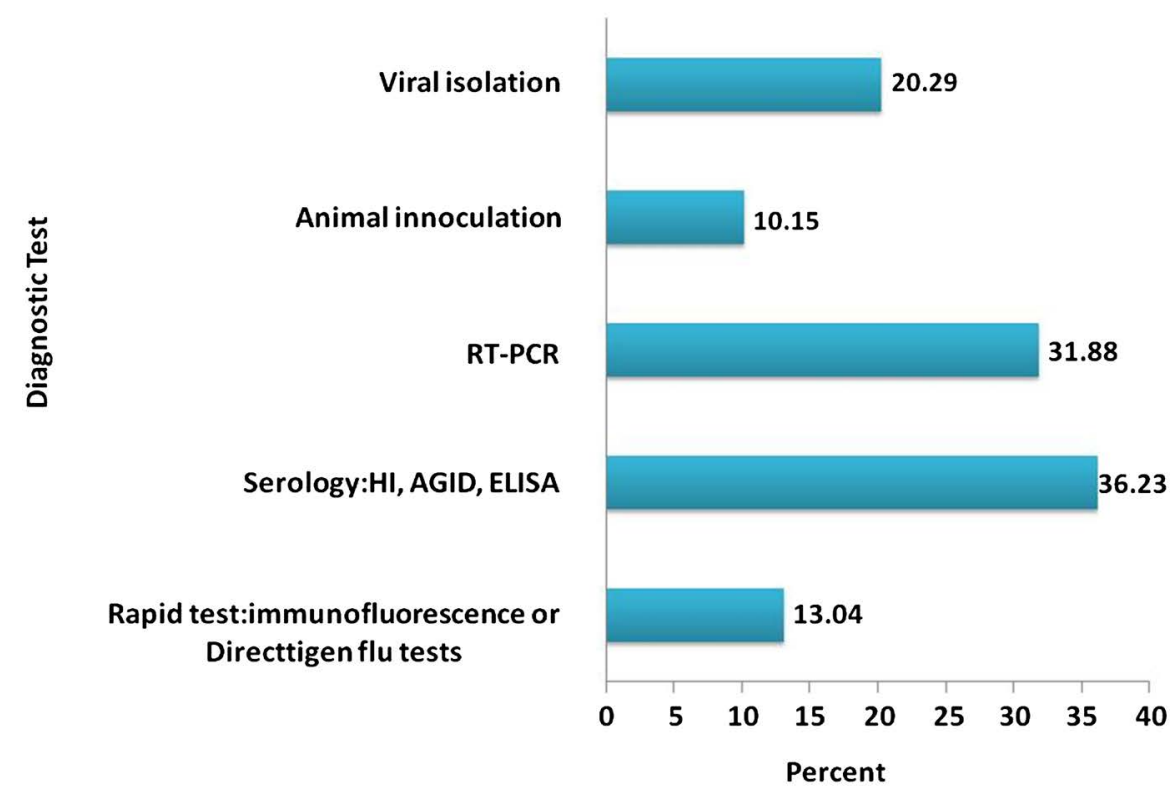

Figure 1. Staff knowledge in respect of basic HPAI diagnostic equipment.

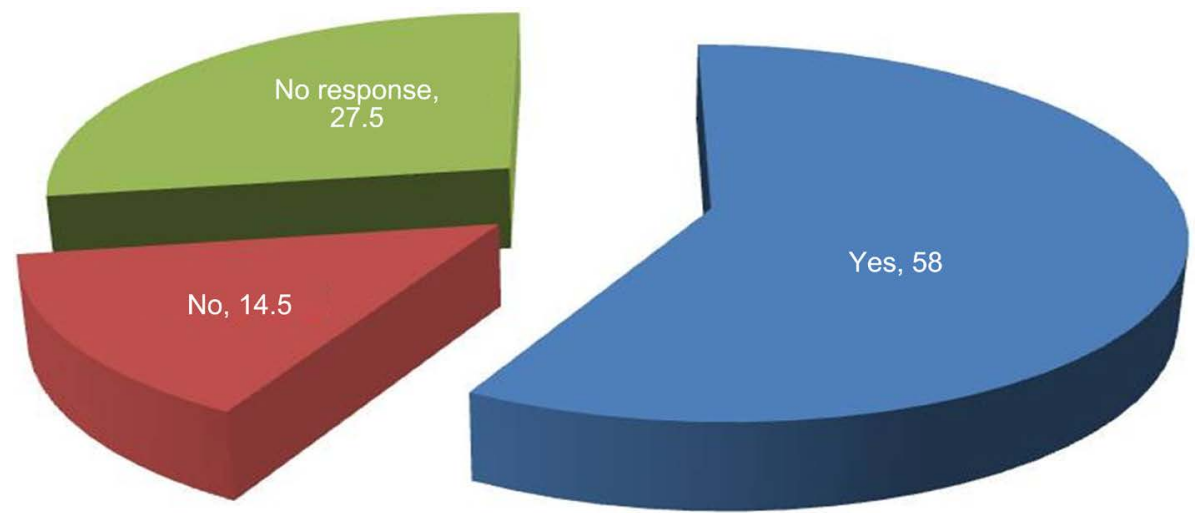

Figure 2. Staff operational ability of basic HPAI diagnostic equipment. 


\section{Acknowledgements}

The authors wish to acknowledge the National Institute for Policy and Strategic Studies (NIPSS) Kuru, Jos-Nigeria for sponsoring the research work as well as granting the permission to publish it.

\section{References}

[1] World Health Organization (2005) Responding to the Avian Influenza Pandemic Threat. World Health Organization, Geneva.

[2] Taubenberger, J.K. and Morens, D.M. (2006) 1918 Influenza: The Mother of All Pandemics. Emerging Infectious Disease, 12, 15-22. http://dx.doi.org/10.3201/eid1209.05-0979

[3] Perroncito, E. (1978) Epizoozia tifoide nei gallinacei. Annali della Academia d'Agricoltura di Torino, 21, 87-126.

[4] OIE (2009) Avian Influenza. Scientific and Technical Review, 28, 5-23.

[5] OIE (2008) Terestrial Manual Chapter 2.3.4-Avian Influenza.

[6] Joannis, T.M., Meseko, C.A., Oladokun, A.T., Ularamu, H.G., Egbuji, A.N., Solomon P., Nyam, D.C., Gado, D.A., Luka, P., Ogedengbe, M.E., Yakubu, M.B., Tyem, A.D., Akinyede, O., Shittu, A.I., Sulaiman, L.K., Owolodun, O.A., Olawuyi, A.K., Obishakin, E.T. and Fasina, F.O. (2008) Serologic and Virologic Surveillance of Avian Influenza in Nigeria, 2006-7. Eurosurveillance, 13, 16.

[7] Thomas, M.E., Bouma, A., Ekker, H.M., Fonken, A.J.M., Stegeman, J.E. and Nielan, M. (2004) Risk Factors for the Introduction of High Pathogenicity Avian Influenza Virus into Poultry Farms during the Epidemic in the Netherlands in 2003. Preventive Veterinary Medicine, 69, 1-3. http://dx.doi.org/10.1016/j.prevetmed.2004.12.001

[8] Ugwu, D.E. (2007) Economic Impact of Avian Bird Flu on Poultry Industry in Nigeria. Pakistan Journal of Social Sciences, 4, 518-524.

[9] Weinberg, A., Mettenbrink, C.J., Ye, D. and Yang, C.F. (2005) Sensitivity of Diagnostic Tests for Influenza Varies with the Circulating Strains. Journal of Clinical Virology, 33, 172-175. http://dx.doi.org/10.1016/j.jcv.2004.12.013 